\title{
DE VERRASSING VAN WILLEMSTAD
}

II

\author{
RONDOM HET PROCES-BORREN ${ }^{1}$ ) \\ DOOR
}

MR. B. DE GAAY FORTMAN

Wie kennis genomen heeft van de krantenverslagen der terechtzittingen van het Hoog Militair Gerechtshof, waar op 2 en 3 October 1930 de zaak tegen den gewezen garnizoenscommandant op Curaçao, kapitein A. F. Borren, behandeld is, zal moeten toegeven, dat daarbij zoo veel van belang voor de geschiedenis van Urbina's aanslag gebleken is, dat de beschrijver van die geschiedenis de nieuwe stof, hem verschaft, niet ongebruikt mag laten liggen.

De eigenlijke strafzaak-Borren betreft slechts een klein onderdeel van deze geschiedenis. Althans formeel heeft de voorzitter van het gerechtshof haar uitdrukkelijk beperkt tot het beleid van den beklaagde als militairen commandant tot op het oogenblik van den overval. Noch zijn gedrag bij en na den overval noch zijn beleid als politieman was in het geding. En juist daarom raakt deze zaak zoo weinig de groote gebeurtenis, omdat de garnizoenscommandant nagenoeg geheel was opgegaan in den politiechef; omdat de militaire beteekenis van het Waterfort eigenlijk nihil was: er was een niet onberispelijke kazerneering van manschappen, die politiediensten deden, en van ,werkers”, die te hunnen behoeve daar waren; er was een politiebureau, en, ja, er was ook een munitiebergplaats.

De militaire bevelhebber Borren vóór 8 Juni 1929 is in het geheele gebeuren van dien dag een niet-onmisbare schakel. Ware Urbina niet gekomen, waarschijnlijk zou niemand eraan gedacht hebben, dat de man, die - ondanks 8 Juni — zoo veel lof inoogst-

$\left.{ }^{1}\right)$ Het eerste artikel in de nummers van Juni en Juli/Aug. 1930. 
te om de vervulling van zijn politietaak, ook nog was geweest.... militaire commandant; en het is niet waarschijnlijk, dat iemand ertoe gekomen zou zijn, hem te verwijten, dat hij als zoodanig gefaald had.

Is het kapitein Borrens schuld, dat hij als garnizoenscommandant tekort geschoten is? Met een beroep op een brief van hem aan den minister van Koloniën, waarvan de inhoud niet nader gebleken is, is erop gewezen, dat hij niet van het begin af het plan heeft gehad, zijn militaire taak te verwaarloozen. Het ligt echter voor de hand, dat het ten slotte zoo ver gekomen is. Jarenlang, van 1921 tot 1928 eigenlijk wel, was het een afbraak in Curaçao. Een der bezuinigingen was de afschaffing van het garnizoen, gepaard gaande met, eigenlijk nog voorafgaande aan, de zooveelste herinrichting der politie, waardoor de garnizoenscommandant met een onvoldoende bezetting stond voor een dubbele taak, waarvan tevoren het kleinste gedeelte aan ongeveer het dubbele getal manschappen was opgedragen. De heer Fruytier, de opperbevelhebber van de landmacht, was nog in 1929 naar ginds vertrokken, nadat hem aan het departement was meegedeeld, zooals hij verklaard heeft, dat de „militaire” begrootingsposten voor bezuiniging in aanmerking kwamen. Er werden ondanks allen aandrang nagenoeg geen mannen gezonden, en ook van deskundige zijde is toegegeven, dat de garnizoenscommandant-politiechef de krachten niet had, om èn de politie èn het garnizoen te bedienen. Zelfs is er een brief van het departement van Koloniën naar voren gebracht, waarin uitdrukkelijk was geschreven, dat, gelet op de taak, welke aan het nieuwe korps militaire politie werd opgedragen, de militaire oefeningen zouden kunnen worden beperkt tot die, welke bevorderlijk moesten worden geacht voor het handhaven van de goede tucht.

En het waren niet alleen het departement en kaptein Borren, die eenzijdig de politietaak van het ,garnizoen" naar voren brachten. Allen leefden in de politiesfeer. Luitenant Hulst zag op den bewusten avond voor zich geen verplichting tot dadelijke medewerking in eenigen vorm, omdat hij niet bij de ,politie" was. Luitenant Berger riep van het plat van zijn woning, toen hij in het fort schieten hoorde, in die richting: „Politie”. De fuselier Nelstein, die op de bank van het wachtgebouw in het fort zat, voegde den chauffeur van een der binnenstormende vrachtauto's toe: „Poco! Poco!” (,Zachtjes aan!’), en rapporteerde aan den brigade-commandant Vaas, dat er twee auto's waren binnengekomen zonder licht, die 
ook niet getoeterd hadden. Brigadier Van Dalen ten slotte vermaande den chauffeur van een der met Venezolanen geladen trucks, om beter uit te kijken, daar hij het motorrijwiel van den brigadecommandant omver gereden had.

Voorwaar! wanneer kapitein Borren niet, min of meer toevallig, nòg garnizoenscommandant was geweest, en het Waterfort nòg fort - de gebeurtenissen van 8 Juni 1929 zouden waarschijnlijk hetzelfde verloop hebben gehad, en dit proces zou er niet geweest zijn. En wanneer Borren gedaan had wat had hem nu verweten wordt te hebben verzuimd, dan zouden, zonder overval, waarschijnlijk politie en garnizoen zonder meer in één hand zijn gebleven, met een tekort aan manschappen, dan zouden nòg de Venezolanen vrijbuiters zijn geweest op Rooi Canarie, en het ontbreken van samenwerking tusschen militaire politie in de stad en burgerpolitie daarbuiten zou wellicht de oorzaak van nòg noodlottiger gebeurtenissen in de toekomst zijn.

Daarom kan ik het proces-Borren niet als iets groots zien.

Het ligt niet in mijn bedoeling, als jurist dit geding te bekijken. Ik reken te schrijven voor een publiek van lezers op rechtsgeleerd en militair gebied. Voor een deskundige beschouwing biedt overigens dit proces zeker stof.

Te laste gelegd is aan kapitein Borren, dat hij verzuimd heeft doeltreffende maatregelen te nemen ter behoorlijke bewaking en verdediging van het Waterfort, voor de veiligheid waarvan hij als militaire commandant verantwoordelijk was, met het bekende noodlottige gevolg, dat de „krijgsmacht” in dat fort is overvallen en het fort zelf overmeesterd. Welke maatregelen hij had moeten nemen, zegt de dagvaarding met zooveel woorden niet. Uit de omschrijving van den overval in dit stuk is daaromtrent echter wel iets te halen, als men leest van "de militair onbewaakte poort" en van "de nagenoeg onbewapende militairen" in het fort. De heeren Bennewitz en Hoorweg, wier verslag waarschijnlijk de grondslag voor deze vervolging zal geweest zijn, althans in zoover dit het gerechtshof tot de slotsom heeft geleid, dat de overgave van den post te Curaçao door het uitgebrachte verslag van den garnizoenscommandant niet kon gehouden worden voor gejustificeerd, hebben naast de afwezigheid aan de fortpoort van een schildwacht - die blijkt zich even verwijderd te hebben en, door wiens schuld staat niet vast, niet vervangen te zijn - en het ongeladen zijn van de pistolen der bezetting in het posthuis, op andere punten gewezen. Veiligstelling van het fort had volgens deze des- 
kundigen de eerste militaire taak van den commandant moeten zijn geweest; hij had moeten denken aan de mogelijkheid van een coup de main op de kazerne van buiten- of van binnenuit; met de 41 werkers van het garnizoen had hij een militaire bewaking moeten vormen; er had een alarmorder moeten zijn; de opberging van wapenen en munitie in het fort was onoordeelkundig; het politiebureau en de vreemdelingendienst hadden niet in het fort moeten zijn ondergebracht, althans niet zoo, dat bij gebreke van afscheiding tusschen politiebureau en kazernement ook dit laatste te allen tijde voor iedereen toegankelijk was.

Voor den leek riekt dit alles te veel naar Oost-Indische ervaring, wanneer men niet vooropstellen wil, dat het achteraf gemakkelijk praten is. Practisch komt het hierop neer, of redelijkerwijs van den Curaçaoschen garnizoenscommandant mocht worden geeischt, dat hij niet alleen denken zou aan - maar ook rekening houden met de mogelijkheid van een overval, als heeft plaats gehad. De bezuinigers van de voorafgegane jaren zouden waarschijnlijk weinig bereid geweest zijn met die mogelijkheid rekening te houden en niet veel hebben over gehad voor afweer van zulk een veronderstelden overval. Maar het waren geen leeken, die èn over de schuldvraag èn over het oorzakelijk verband tusschen de genoemde tekortkomingen en het slagen van den overval te beslissen hadden.

De verdediging heeft geen clementie gepleit; het was trouwens niet noodig na de clemente vordering van den advocaat-fiskaal. Deze toch heeft, na den beklaagde te hebben voorgehouden, dat hij de schuld droeg van den dood der drie gevallenen, van de uitlevering van Perez, van de nationale schande, .... vijf dagen gevangenisstraf geëischt.

Juridische en militair-technische vragen heeft de verdediger gesteld: was Borren de bevelvoerende militair of kan hij zich dekken achter zijn opperbevelhebber, die in hem slechts zag een commissaris van politie, als zoodanig nog staande onder het wettelijk hoofd der politie, den procureur-generaal? Was het fort een versterkte of bezette plaats? Is inderdaad strafbaar verzuim den beklaagde te verwijten? Vooral deze laatste vraag, de schuldvraag, was zoo belangrijk, omdat, ondanks de verzuimen van kapitein Borren, de overval volgens meer dan één deskundig oordeel waarschijnlijk niet zou hebben plaats gevonden, als er een oorlogsschip was geweest of voldoende manschappen waren uitgezonden, althans om Rooi Canarie onder de militaire politie te brengen. Zijn de aanvallers wel opstandelingen geweest in den zin van de straf- 
bepaling, waarvan de toepassing werd gevraagd? Deze laatste, min of meer rhetorische, vraag scheen het sterkste wapen in de hand der verdediging.

Het vonnis van het Hoog Militair Gerechtshof van 14 October 1930 is in zijn geheel te vinden in de Nederlandsche Jurisprudentie 1930, bladz. 1391. Alle juridisch en feitelijk verweer vindt men erin weerlegd. Behalve de genoemde verzuimen heeft het hof in aanmerking genomen het gaan wonen van den commandant op Plantersrust, door gouverneur Brantjes hem toegestaan. Ook een der vroegere garnizoenscommandanten, de toenmalige kapitein Bierman, heeft dit in het Politiek Econ omisch Weekbla d indertijd als een verkeerden maatregel naar voren gebracht. Dat er sprake is geweest van opstandelingen, immers aan het Nederlandsch gezag onderworpenen en tegen dat gezag opstandigen, heeft het hof afgeleid o. a. uit een verklaring van luitenant Berger na ingesteld onderzoek, dat voor het meerendeel de aanvallers op Curaçao gevestigd waren, en hieruit, dat zij hun wil aan den militairen commandant en door bedreiging met plundering en brandstichting aan den hoogsten militairen gezagvoerder hebben weten op te leggen en beiden met geweld hebben meegevoerd. Opmerkelijk is het, dat in de uitspraak het niet-uitoefenen van den politiedienst door de militaire politie op Rooi Canarie, tot ontlasting van kapitein Borren aangevoerd, hem als verzwarende omstandigheid wordt aangerekend: het had hem blijkbaar voorzichtiger gemaakt moeten hebben. Het openstellen van het fort voor iederen kwaadwillige en iederen spion, die met eigen oogen van de geheel onvoldoende bewaking zich zou wenschen te overtuigen, wordt als het ware als een uitlokking tot den overval beschouwd. En wat het geringe aantal politie-militairen betreft - hierin ligt geen verontschuldiging, zegt het hof, want de beklaagde had moeten bedenken, dat de verzekering van de veiligheid zijner troepen en van de ongestoorde beschikking over het Waterfort, waarin die troepen gelegerd en al de beschikbare machtsmiddelen geborgen waren, zijn eerste en hoogste taak was en bleef. Er is in deze sententie, die eindigt met een veroordeeling tot een gevangenisstraf van één dag, wel een en ander, dat verwondering wekt; dit vooral, dat „de eerst na den overval genomen maatregelen hebben doen zien, (dat) die veiligheid met de beschikbare middelen en zonder dat daarvoor militairen aan hun politietaak behoefden te worden onttrokken, had kunnen zijn verzekerd". Tenzij het hof hier doelt op iets, dat bij de openbare behandeling niet gebleken of het publiek 
ontgaan is, klinkt deze uitspraak vreemd. Immers de heer Hoorweg heeft opgemerkt, dat de tegenzin in de militaire politie zich ook hierin geuit had, dat op 8 Juni 1929 de burgerij zich vrijwel geheel afzijdig gehouden had, terwijl daarnà 400 vrijwilligers zich aanmeldden, waaruit, zooals luitenant Berger verklaarde, ook vóór den overval hulp voor de politiemilitairen zou zijn te vormen geweest.

Het is niet veel, wat de pers over het proces heeft nagepleit. $\mathrm{Zij}$ heeft verslagen gegeven met plaatjes, waarop hoofdpersonen als kapitein Borren en ex-gouverneur Fruytier niet steeds in de naar omstandigheden meest gewenschte houding voor het voetlicht kwamen. Het meest trok nog de aandacht de overweging ten aanzien van de op te leggen straf, dat aan den dag gekomen was, hoe de Nederlandsche regeering in het openbaar en ook in geschrifte tegenover den gouverneur van Curaçao, opperbevelhebber van de aldaar gevestigde krijgsmacht, de politietaak der troepen steeds op den voorgrond heeft geschoven en aan haar zuiver militaire functie nagenoeg geen aandacht heeft gewijd; en deze: „dat beklaagde, op wien practisch is gedemonstreerd dat de ondanks zijn aanhoudend aandringen niet op volle sterkte gebrachte Rijkslandmacht niet te zelfder tijd kan dienen tot bescherming der kolonie, waarvoor de wetgever haar blijkens artikel 99 van het Regeerings-reglement heeft bestemd, en tot uitoefening van den politiedienst op Curaçao, deze proefneming niet al te duur zal mogen bekoopen”. De T eleg ra af diesprak van ,een armzalige vertooning met de schuldigen als regisseurs", niet onduidelijk te kennen gevende, dat de Nederlandsche regeering de in de eerste plaats schuldige was, gaf in teekening een ,impressie in den tourniquet van restaurant „Central” ' met als onderschrift: „Kapitein Borren draait er in en ir. Fruytier draait er uit".

„De regeering gevonnist" schreef het Algemeen Handelsblad, en stelde als meer dan een ander blad tegenover Borrens veroordeeling de „dankbetuiging” aan Fruytiers adres.

Het Tweede-kamerlid Vos stelde aan de regeering de vraag, of zij de hand had in de vervolging van kapitein Borren, waarop hij ontkennend bescheid ontving. Het beslissende woord in deze is gesproken door den gouverneur van Curaçao na advies van het hof van justitie aldaar. Het vreemde van deze regeling, die in dit geval echter geen bezwaar opleverde, valt op, wanneer men bedenkt, dat deze gouverneur zelf bij een gebeurtenis, als waarvoor verwijzing plaats vindt, betrokken kan zijn geweest. 
Vermakelijk was de vergissing, die de $\mathrm{Nieu}$ we Rot terdamsche Courant maakte. Haar verslaggever had den advokaatfiskaal een joodschen smid hooren prijzen, die met anderen het vertrek van de Maracaibo had willen sabotteeren, wanneer de gouverneur daartoe toestemming zou hebben gegegeven. De redactie wilde dezen Oosterschen ambachtsman huldigen, maar zij had misverstaan: geen joodsche smid maar de loods Smit was de persoon, wien de lofprijzing gegolden had.

Kapitein Borren heeft geweigerd gratie te vragen. Anderen hebben het voor hem gedaan. Ten onrechte misschien. Hier leek ongevraagde gratie op haar plaats; gratie om de ongelijke beoordeeling van de bij het drama van 8 Juni 1929 rechtstreeks en zijdelings betrokkenen zoo veel mogelijk ongedaan te maken. Er zijner, die er kwaad noch goed van gehoord hebben; er zijn er, die er geen, of althans ten slotte geen blijvend, nadeel van geleden hebben; kapitein Borren zou alleen de kwade kansen krijgen. Ruim 1200 personen hebben het gratieverzoek ondersteund, onder welke 300 Curaçaoenaars met den ondervoorzitter van den raad van bestuur, twee leden van den Kolonialen raad en zelfs leden van de rechterlijke macht. Na maanden wachten is het verzoek geweigerd. Echter zal de Amsterdamsche dame, die - nogal naïef aanbood voor kapitein Borren te gaan zitten, zeker niet aan haar aanbod gehouden worden.

Met de vervolging van kapitien Borren stemde in De Stand a ard. Van een meten met twee maten kon volgens dit blad in dit verband niet gesproken worden. De „misselijke houding” van den gouverneur moest met ontslag wegens ongeschiktheid gestraft worden, maar voor een andersoortig ambt was deze daarom niet ongeschikt. De gouverneur was niet de eerst geroepene om aan een gevecht deel te nemen, wat wel de taak der oficieren is, als er gevochten moet worden. Wat gebeurt er met de andere officieren? zoo vroeg het blad.

Intusschen was toen reeds bekend, dat beide officieren Curaçao hadden verlaten en aan luitenant Hulst ontslag uit den militairen dienst was verleend. De vraag van $\mathrm{De} \mathrm{S}$ t a n d a a rd houdt echter niet voldoende rekening hiermee, dat in de strafzaak uitsluitend aan de orde was kapitein Borrens gedrag vóór den overval, en dat de beide luitenants, die soortgelijke taak als hun militaire chef niet hadden, door gelijke verwijten niet getroffen konden worden. Van luitenant Hulst, die niet bij de politie was geplaatst, maar wel als 
officier van munitie en bewapening een militaire taak had, hoort men in de geschiedenis van den overval nagenoeg niet. Ofschoon hij met luitenant Berger op het woningplat het schieten in het fort gehoord had, bleef hij tehuis, met de bij hem saamgekomen militairen, waar hem later ook de telefonische mededeeling, dat er niet geschoten mocht worden, bereikte en te kwart voor drieën de tijding van de afreis met de Maracaibo. Hij was bovendien de adjudant van den gouverneur. Men kan vragen, wie van beide officieren de aangewezen vervanger van kapitein Borren was, toen deze in Venezolaansche gevangenschap verkeerde, en het antwoord kan een leek zeker niet geven. Verwarrend werkt ook hier weer de dubbele taak van den garnzioenscommandant: militair gesproken was luitenant Hulst de aangewezene, maar, als gezegd, deze stond buiten de politieorganisatie, al was het voorgekomen, dat hij bij ontstentenis ook als politiechef den kapitein vervangen had. Maar die gevangenschap van kapitein Borren is ook niet doorgedrongen tot luitenant Berger, die dadelijk op pad ging en last gegeven had, dat bij luitenant Hulst zich de manschappen zouden verzamelen. Het schijnt, dat kapitein Borren op weg naar zijn eerste onderhoud met den gouverneur van niemand vergezeld is geweest, maar niettemin zich als gevangene beschouwd heeft in dien zin, dat hij niet daadwerkelijk tot verzet kon optreden.

Wat kapitein Borren betreft, zou volgens een bericht in het $\mathrm{K} \mathrm{o-}$ lonia al We e kbla d na zijn veroordeeling nog aan de orde komen de vraag, of hij in militairen dienst kan blijven. In dit verband is zeker der vermelding waard, dat de heeren Hoorweg en Bennewitz kapitein Borren geprezen hebben om hetgeen hij in een der militaire politie vijandige omgeving heeft tot stand gebracht, en ook om den moed, waarmee hij in het fort door zijn vijanden heen gereden is, al werd daarbij vermeld, dat hij, voor zoover hij als politieman zijn doel bereikte, dit deed ten koste van zijn militaire taak, en dat op het oogenblik van moed na zijn gevangenschap een ineenstorting van zijn moreel volgde, waardoor het kon voorkomen, dat hij met Urbina naar de munitiebergplaats ging, al dacht hij wellicht, dat de Venezolanen, die al gevonden hadden, en zich leende tot het défaitistisch onderhoud met den gouverneur. Wat dit laatste betreft, ziet men bij kapitein Borren een soortgelijk verschijnsel als bij den gouverneur, gelijk ik in mijn vorig stuk opmerkte, nl. gemis aan besef, dat met de gevangenschap zijn taak als raadsman van den gouverneur was opgehouden, ofschoon hij wellicht geen uitdrukkelijk wets- of reglementsartikel tot zijn beschikking had, om hem dat besef bij te brengen. 
Over het noodlottig onderhoud tusschen de heeren Fruytier en Borren loopen de verhalen uiteen. Is de gouverneur aanstonds bereid geweest, het hoofd in de schoot te leggen, toen kapitein Borren Urbina's boodschap had overgebracht met zijn eigen meening, dat tegenstand nutteloos moest worden geacht, of heeft de kapitein sterken aandrang moeten uitoefenen? Luitenant Berger, die dit onderhoud gedeeltelijk heeft bijgewoond, heeft verklaard, dat de gouverneur dadelijk alles goed vond, wat de garnizoenscommandant voorstelde, nl. de inwilliging van Urbina's eischen. Verder heeft deze getuige verklaard, dat de gouverneur uitdrukkelijk de order gegeven heeft, dat er niet geschoten zou mogen worden. Des oud-gouverneurs opmerking, dat hij zich dit niet meer herinnerde, werd in de rechtszaal met een onderdrukt gemompel ontvangen. Maar doet het veel ter zake? Lag het afzien van verzet niet opgesloten in het besluit om op Urbina's voorstellen in te gaan? Naar verluidt, zou Urbina's bedreiging van plundering en brandstichting, in het bijzonder wat de Isla betreft, ook nog zijn neergelegd in een schrijven zijnerzijds aan een van het personeel der C. P. I. M., wiens medewerking tot voorkoming van de uitvoering dezer bedreiging werd ingeroepen. Onbegrijpelijk mag het echter heeten, dat, wanneer men den ernst der bedreiging aanneemt, bij hen, die de beslissing in handen hadden, de vraag niet schijnt opgekomen te zijn, of het woord van den rebellenhoofdman wel te vertrouwen was.

Van luitenant Berger is ook de mededeeling, dat hij hulp van de C. P. I. M. gevraagd heeft, en hem die geweigerd is, waarna later het telefonisch aanbod van die zijde aan den gouverneur in tegenwoordigheid van dezen officier gevolgd is, wat hem begrijpelijkerwijs weinig aangenaam stemde.

De advocaat-fiskaal heeft kapitein Borren de bevrijding van Perez verweten. Waarop dit berust, is, als ik goed verstaan heb, bij de openbare behandeling niet gebleken. Van personen, destijds op Curaçao, hoorde ik, dat kapitein Borren in de gevangenis de vrijlating en daarmee de overlevering aan Urbina en de zijnen van Perez zou bevolen hebben. Hoe dit te rijmen is met de destijds vermelde veroordeeling van Venezolanen door den Curaçaoschen rechter, waarover ik in mijn vorig stuk gesproken heb, is mij niet opgehelderd. Ook niet krachtens welke bevoegdheid aan het bevel van den kapitein zou uitvoering zijn gegeven. Wel zou deze zich later beroepen hebben op den last van den gouverneur, die echter op zijn beurt zou hebben betwist, dien gegeven te hebben. In 
ieder geval is gouverneur Fruytier van dezen eisch der Venezolanen, een der voorwaarden voor Urbina's aftocht waarschijnlijk, op de hoogte geweest. Het is nu niet meer zoo onbegrijpelijk, waarom de regeering op alle vragen, haar over deze zaak gesteld, het antwoord is schuldig gebleven.

Een andere zaak, die mij van Curaçaosche zijde, waarmee ik bedoel: uit Curaçao, is meegedeeld, is die van het S.O.S.sein, na den overval door den procureur-generaal opgegeven ter verzending aan den radiodienst. Het zou echter niet in den vorm, waarin het aangeboden was, zijn uitgezonden, maar de dienstdoenden ambtenaar zou zich bepaald hebben tot een algemeenen oproep om hulp, die echter gelukkig geen gevolg schijnt te hebben gehad.

Onder den voorganger van gouverneur Fruytier is, als gezegd, de afbraak begonnen. Het oude garnizoen verliep langzamerhand, de uitzending van politiemilitairen vlotte niet, ondanks herhaalden aandrang van den gouverneur, mede in verband met een eerst niet verwachte uitbreiding der petroleumbedrijven, ook op Aruba, en deugde niet. Er is gesproken van een dokter, die de detacheering niet bevorderde. En toch werden er nog soldaten gebruikt voor werk, dat eigenlijk door Openbare werken of een ander civiel departement had moeten worden gedaan, als het maken van kasten voor de openbareleeszaal en het zetten van begrootingsstukken ter drukkerij van De Curaçaosche Courant. Deschutterij werd inmiddels afgeschaft. Opde Isla alleen werd een kern voor eigen verdediging gevormd; van de daar aanwezige reserveofficieren werd voor de landsverdediging geen gebruik gemaakt. De tegenstand van den Kolonialen raad met het wat dwaze incident, toen kapitein Borren als bestuursgemachtigde de door den waarnemenden gouverneur goedgekeurde rede voorlas, heeft zeker aan den toestand geen goed gedaan; mede op rekening daarvan mag worden geschreven de beperking van den militairen politiedienst tot het stadsdistrict. Gouverneur Brantjes, destijds afwezig, heeft verklaard, dat hij in deze zaak aan Borrens zijde stond en van de zijde van den minister zou hem ook een tevredenheidsbetuiging geworden zijn. Daarbij kwam de wonderlijke verhouding van den leider van den politiedienst tot den procureur-generaal, die, zeker niet in de eerste plaats door zijn eigen schuld, wel formeel hoofd der politie bleef, maar - in tegenstelling met zijn voorganger, die voor een procureur-generaal wel wat al te zeer in kleinigheden afdaalde - het in werkelijkheid niet meer dan administratief was. Dat dit stelsel ongewenschte gevolgen had, waar de oude bur- 
gerpolitie gebleven was, en daar niet een erkend bekwaam vakman als kapitein Borren de teugels kon opnemen, is begrijpelijk. Het lijkt ook hier weer op een vooruitloopen op wat worden moest, de overneming van de politietaak door de militaire politie, waarvoor het tweede district, waarin Rooi Canarie gelegen was, het eerst in aanmerking zou gekomen zijn.

Was er eigenlijk wel recherche? is gevraagd naar aanleiding van de opmerking, hier te lande gemaakt, dat de recherche toch iets had moeten merken. Inderdaad - zij is er gekomen met luitenant Berger, die eerst het werk met één of twee sergeant moest afdoen, later met acht man. Als de geheele militaire politie bleef deze recherche tot het stadsdistrict beperkt, en wat op Rooi Canarie broeide, kon tot haar niet doordringen. Wat van de toestanden daar gebleken is, tart alle beschrijving. Vijfhonderd woningen met Venezolanen, las ik ergens, schots en scheef door elkaar geplaatst, een verzamelplaats van vaak ongure elementen, een broeinest van ongerechtigheid, met een politiepost onder ondeskundige leiding van een gewezen brigadier van het voormalige garnizoen, waar ook de Islapolitie niets kon doen.

Meer dan één pamflet blijkt van Venezolaansche zijde verspreid te zijn. Kapitein Borren heeft er althans één gehad, en daarover gesproken met den Venezolaanschen consul, die het bestuur tegen over de revolutionaire elementen te lankmoedig vond, en het begrijpelijkerwijs 't best vond, onvindbaar te zijn, toen Urbina den baas speelde.

De geschiedenis van het oorlogsschip, waarop de gouverneur Fruytier zou hebben aangedrongen, blijkt aldus geweest te zijn. Vóór zijn vertrek had de minister hem gesproken over de zending van een oorlogsschip in het voorjaar van 1929. Op Curaçao gekomen, heeft de heer Fruytier getelegrafeerd: als het komt, laat 't dan in Mei hier zijn in verband met de presidentsverkiezing in Venezuela, en daarna zou hij volgens zijn verklaring nog op de komst van een oorlogsschip telegrafisch hebben aangedrongen.

Tegen Rafael Simon Urbina en Gustavo Machado is op vordering van het openbaar ministerie bij beschikkingen van $28 \mathrm{Juli}$ 1930 van den rechter in het benedenwindsche kantongerecht rechtsingang met last tot instructie en gevangenneming verleend ter zake van het ondernemen van een aanslag met het oogmerk om den gouverneur van de vrijheid te berooven, althans van openlijke geweldpleging met vereende krachten tegen personen en goederen, terwijl dat geweld den dood ten gevolge heeft, of wel feitelijke aanranding van den persoon van den gouverneur. 
Den 23sten November 1930 is op het militaire kerkhof op Curaçao een grafmonument onthuld ter eere van de nagedachtenis van de gesneuvelde militairen Marcusse, Vaas en Van Zuilen. Hulde aan hen, die hiertoe het initiatief namen, en aan de bekende Curaçaosche milddadigheid, die de uitvoering heeft mogelijk gemaakt. Terecht is gewezen op den allerwonderlijksten indruk, die het maken moet, dat deze Nederlandsche militairen, die, in een deel van Nederland gevallen voor een Nederlandsche zaak, het moeten stellen met een opschrift in een taal, die zij waarschijnlijk niet verstaan hebben, in de taal van hen, wier slachtoffers zij werden.

Dr. Bergmann, de oud-directeur van den openbaren gezondheidsdienst in Curaçao, die oude grieven tegen het toenmalig gouvernement heeft, heeft gemeend, in deze zaak een woord te moeten meespreken, o. a. door een Open brief aan den minister van Koloniën, geplaatst in het $\mathrm{Nieuws}$ van den Dag van Nederlandsch-Indië, met klachten tegen het beleid van gouverneur Brantjes.

De heeren Hoorweg en Bennewitz hebben als hun meening uitgesproken, dat onder bekwame leiding in het fort weerstand had kunnen worden geboden, en dat later meer dan eens had kunnen worden beproefd het te heroveren en de Venezolanen te overmeesteren. Voorts zou kapitein Borren, wanneer een nadere vraag op de telefonische medeeling van luitenant Berger hem van den ernst van den toestand op de hoogte had gebracht, aan de Overzijde de daar aanwezige militairen hebben kunnen verzamelen en met hen, desnoods in opgeëischte auto's, een tegenaanval doen. En luitenant Berger had, wanneer hij de leiding had genomen, als kapitein Borrens gevangenschap tot hem doorgedrongen was, op eigen initiatief en verantwoording maatregelen kunnen nemen, zooals hij reeds begonnen was, toen de gouverneur Urbina's eischen inwilligde.

Hiermee ben ik aan het einde van de taak, die ik mij gesteld heb. De bedoeling is geweest, zooals ik in het begin van mijn vorig stuk gezegd heb, vast te leggen, zoo veel mogelijk, wat er gebeurd is. Zoo veel mogelijk; ik zal wel fouten gemaakt hebben. Al te zeer is stilzwijgendheid betracht. Daarom heb ik nagenoeg steeds mijn bronnen genoemd, Niet als beoordeelaar ben ik opgetreden. Wanneer ik eenige malen een „onbegrijpelijk" of „onverklaarbaar” heb doen hooren, een enkele maal een afkeurend woord niet teruggehouden heb, was dit, als ik meende daarmee een vrijwel algemeen oordeel weer te geven.

Amsterdam, 24 Januari 1931. 